Green, H. H. (1944). Proc. Nutr. Soc. 1, 177.

Keener, H. A., Percival, G. P., Morrow, K. S. \& Ellis, G. H. (1947). J. Dairy Sci. 30, 557.

Liebscher, W. (1937). Proc. 11th World Dairy Cong., Berlin, 1, 130.

Mitchell, R. L. (1944). Proc. Nutr. Soc. 1, 183.

Owen, E. C. (1947). J. Dairy Res. 15, 142.

Owen, E. C. (1948). Nature, Lond., 160, 78.
Pearson, R. M. \& Smith, J. A. B. (1943a). Biochem. J. 37, 142.

Pearson, R. M. \& Smith, J. A. B. (1943b). Biochem. J. 87, 148.

Pyenson, H. \& Tracy, P. A. (1945). J. Dairy Sci. 28, 401. Smith, J. A. B. \& Baker, F. (1944). Biochem. J. 38, 496. Tosic, J. \& Mitchell, R. L. (1948). Nature, Lond., 162, 502. Zentmyer, G. A. (1944). Science, 100, 294.

\title{
The Turnover of Radioactive Phosphate Injected into the Subarachnoid Space of the Brain of the Rat
}

\author{
By O. LINDBERG AND L. ERNSTER \\ Wenner-Gren Institute, Department for Metabolic Research, University of Stockholm
}

(Received 4 July 1949)

In the literature little information is given on the rate of phosphorylations in the brain, and even the few studies which have been made in this field are with. out real value because of unsatisfactory experimental conditions and methods. Perhaps the main reason for this neglect is that many acidic substances hardly penetrate into the brain at all from the remainder of the organism. The 'blood-brain barrier' acts as an extremely effective obstacle to any exchange of such substances between the central nervous system and the rest of the organism, and thus makes the former with respect to permeability a virtually 'closed' system. Hevesy $(1939 a, b)$ and Hevesy \& Hahn (1940) have shown that even a fairly long time after subcutaneous or intravenous injection of ${ }^{32} \mathrm{P}$ only a very small fraction of the substance could be found in the brain and a number of workers have, erroneously, interpreted these results as implying that the brain must have a very low turnover rate (Borell \& Örström, 1947; Reiss, Badrick \& Halkerston, 1949). This, however, by no means follows from the experimental findings.

Bakay \& Lindberg (1949), in their investigations on the role of the cerebrospinal fluid in the metabolism of the brain, showed that ${ }^{32} \mathrm{P}$ injected intracisternally spread very rapidly into different parts of the rabbit's brain, and that after a relatively short time a considerable part of the newly introduced phosphate could be found in organic linkage. But these experiments did not yield a detailed picture of the metabolic conditions. The object of the present study was to investigate the extent and the rate of incorporation of the newly introduced phosphate into the various acid-soluble phosphorus fractions and also the turnover rate of these fractions inside the barrier.

\section{EXPERIMENTAL}

Operative procedure. White rats (100-150 g.) were injected with about $0.1 \mathrm{ml}$. of a solution containing approx. 0.1 mc. ${ }^{32} \mathrm{P}$ and a negligible amount of phosphate. The injections were made without anaesthetic as follows: the injection needle was placed in the sutura sagittalis on a level with the connecting line between the two eyes and forming an angle of about $45^{\circ}$ with the frontal plane (see Fig. 1) and
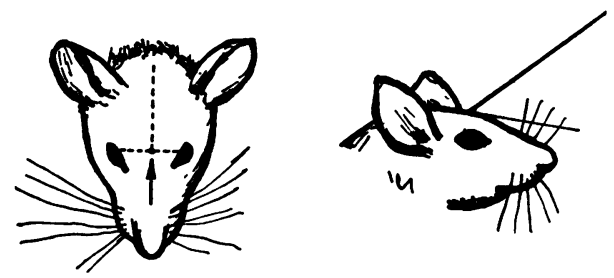

Fig. 1. Intracranial injection on rats.

was introduced by rotation under moderate pressure. The injected solution thus enters the space between the bulbi olfactorii, whence it can spread easily in the subarachnoid space without injuring important motor or vegetative centres. Following the injection the condition of the animals was observed. Usually no change was noted. In the cases in which convulsions, paralysis, or other symptoms of relatively severe brain injury were observed, however, the animals were either rejected or used for longer experimental periods.

Preparation of samples. The animals were killed by drowning in acetone cooled to -60 to $-70^{\circ}$ with $\mathrm{CO}_{2}$, in which they died instantly. They were taken out about $15 \mathrm{~min}$. after death and kept in solid $\mathrm{CO}_{2}$ until required.

The brains were removed under continuous cooling with solid $\mathrm{CO}_{2}$ with the aid of a hammer and chisel (see LePage, 1946). A small portion of the medulla oblongata (1-5 mg.) was placed directly in the electron counter to see whether the labelled phosphate had entered and spread in the brain. 
The brains were ground to a fine powder in a mortar cooled with solid $\mathrm{CO}_{2}$ and extracted with approx. $15 \mathrm{ml}$. saturated $\left(\mathrm{NH}_{4}\right)_{2} \mathrm{SO}_{4} /$ brain for about $15 \mathrm{~min}$. with the aid of a compressed-air driven rotating glass rod. During extraction the temperature was not allowed to rise above $-10^{\circ}$; this was accomplished by cooling with an ice-salt mixture. The samples were then filtered through a Büchner funnel $(4 \mathrm{~cm}$.) using double filter papers. The filter was washed with approx. $5 \mathrm{ml}$. extraction solution. Approx. $0.05 \mathrm{ml}$. of the extract was dried rapidly under a heating lamp and the radioactivity measured in the electron counter. Having thus obtained an approximate value for the ${ }^{32} \mathrm{P}$ content of the extract, a fraction (usually l-2 ml.), corresponding to 105 counts/min., was diluted to $100 \mathrm{ml}$., $2 \mathrm{ml}$. of this diluted extract were taken for each analysis.

\section{Analytical methods}

Apart from the isotope experiments a number of ordinary phosphate determinations were made. For these the animals were decapitated. The brains were removed, weighed and extracted with $10 \%(w / v)$ trichloroacetic acid. Total and labile $\mathbf{P}$ determinations were made on measured fractions of the extract $(a)$ after $10 \mathrm{~min}$. hydrolysis with N-HCl at $100^{\circ}$, and $(b)$ after combustion with $\mathrm{H}_{2} \mathrm{SO}_{4}$. The $\mathrm{P}$ value after hydrolysis was considered to consist of the sum of the orthophosphate, creatine phosphate, and the fraction representing the two labile $P$ atoms of adenosine-triphosphate (labile ATP-P) of the sample, while the difference between total and labile $P$ corresponds to the phosphate content of the 'residual fraction'. Each estimation in the two types of experiment was made in quadruplicate.

Phosphate determinations were carried out according to the methods of Fiske \& Subbarow (1925) and Briggs (1922). The colour was measured at $660 \mathrm{~m} \mu$. in a Klett Summerson photometer.

Radioactivity was determined in a Geiger-Müller counter following precipitation of the phosphate as $\mathrm{MgNH}_{4}$ salt (Lindberg, 1946). To determine activity of the orthophosphate fraction the phosphate was precipitated directly by Fiske's reagent. The activity of the creatine phosphate was determined after $4 \mathrm{~min}$. hydrolysis with $\mathrm{N}-\mathrm{HCl}$ at $60^{\circ}$; with these conditions, according to hydrolysis curves made with the pure substances in question, $84 \%$ of the creatine phosphate and $10 \%$ of the labile ATP-P is split. The values recorded in Table 1 were calculated using this correction.
Using a similar correction the activity of the labile ATP-P was determined after $10 \mathrm{~min}$. hydrolysis with $\mathrm{N}-\mathrm{HCl}$ at $100^{\circ}$. The total activity of the samples was measured following combustion with $\mathrm{H}_{2} \mathrm{SO}_{4}$. The values for ATP obtained by acid hydrolysis were checked in some experiments by enzymic splitting with adenosine pyrophosphatase (apyrase) and with myosin. Potato apyrase was purified according to Kalckar (1944). The samples were incubated in succinate-borate buffer, $\mathrm{pH} 6.0$ at $30^{\circ}$. Myosin was purified according to Bailey (1942); the incubation was carried out according to DuBois \& Potter (1943).

Activity of the triosephosphate fraction was determined after 5 min. hydrolysis with $2 \mathrm{~N}-\mathrm{NaOH}$ at room temperature. Hexosediphosphate activity was measured after incubation with aldolase, followed by determining the activity of the triosephosphate formed. Aldolase was isolated and the samples were incubated according to Herbert, Gordon, Subrahmanyan \& Green (1940). The phosphate which, after 10 min. hydrolysis at $100^{\circ}$ with $\mathrm{N}-\mathrm{HCl}$, is still present in organic linkage is called 'residual fraction'.

\section{RESULTS AND DISCUSSION}

The results of the isotope experiments are shown in Table 1. A few experiments which displayed notable anomalies, probably because of inadequate cooling during extraction or other technical errors, were rejected. The values, given in percentages of the total activities of the samples, are in most cases the mean values of two or three experiments.

The activity of the labile ATP-P, determined in two cases by plotting the curves for the enzymic splitting with apyrase, which like acid hydrolysis revives two phosphate groups, gave $110 \cdot 1$ and $100.4 \%$, respectively, of the values obtained by acid hydrolysis. With myosin, which hydrolyses only the terminal phosphate group, in another experiment $44.4 \%$ of the acid hydrolysis value was obtained; this corresponds to $88.8 \%$ of the value obtained with phosphate. Thus these control experiments provide a satisfactory check of the methods. No activity in the form of hexosediphosphate or triosephosphate could be demonstrated.

Table 1. Distribution of intracranially injected ${ }^{32} \mathrm{P}$ among the acid-soluble phosphate fractions in rat brain

Total ${ }^{32} \mathrm{P}$ content of the sample in the form of

\begin{tabular}{|c|c|c|c|c|c|}
\hline \multirow[b]{2}{*}{$\begin{array}{c}\text { Duration } \\
\text { of exp. }\end{array}$} & \multirow[b]{2}{*}{$\begin{array}{c}\text { No. } \\
\text { of exps. }\end{array}$} & \multirow[b]{2}{*}{$\begin{array}{c}\text { Ortho-P } \\
(\%)\end{array}$} & \multicolumn{2}{|c|}{ Labile P } & \multirow[b]{2}{*}{$\begin{array}{c}\text { 'Residual' } \mathbf{P} \\
(\%)\end{array}$} \\
\hline & & & $\begin{array}{c}\text { Creatine } \mathrm{P} \\
(\%)\end{array}$ & $\begin{array}{c}\text { Labile ATP-P } \\
(\%)\end{array}$ & \\
\hline 2 min. & 2 & $59 \cdot 1$ & $6 \cdot 3$ & $28 \cdot 9$ & $5 \cdot 7$ \\
\hline 5 & 3 & $48 \cdot 1$ & $9 \cdot 0$ & $36 \cdot 4$ & $6 \cdot 5$ \\
\hline 10 & 1 & $44 \cdot 9$ & $11 \cdot 1$ & $36 \cdot 4$ & $7 \cdot 6$ \\
\hline 26 & 2 & $44 \cdot 5$ & $13 \cdot 9$ & $36 \cdot 8$ & $4 \cdot 8$ \\
\hline 45 & 2 & $36 \cdot 0$ & $13 \cdot 8$ & $40 \cdot 3$ & $9 \cdot 9$ \\
\hline 65 & 2 & $36 \cdot 5$ & $12 \cdot 6$ & $35 \cdot 6$ & $15 \cdot 3$ \\
\hline 103 & 3 & $36 \cdot 7$ & $15 \cdot 1$ & $31 \cdot 3$ & $16 \cdot 9$ \\
\hline $3 \mathrm{hr}$. & 2 & $31 \cdot 1$ & $15 \cdot 2$ & $34 \cdot 7$ & $19 \cdot 0$ \\
\hline 4 & 3 & 29.9 & $18 \cdot 1$ & $34 \cdot 1$ & $17 \cdot 9$ \\
\hline 8 & 1 & $24 \cdot 0$ & $16 \cdot 7$ & $33 \cdot 0$ & $26 \cdot 3$ \\
\hline 16 & 1 & $30 \cdot 7$ & $16 \cdot 6$ & $26 \cdot 9$ & $25 \cdot 8$ \\
\hline 24 & 2 & $34 \cdot 3$ & $11 \cdot 1$ & $28 \cdot 7$ & $26 \cdot 0$ \\
\hline
\end{tabular}


Table 2. The distribution of ${ }^{32} \mathrm{P}$ between orthophosphate and the labile phosphate esters

(a) Ratio orthophosphate/labile phosphate

\begin{tabular}{|c|c|c|c|c|c|}
\hline \multirow[b]{2}{*}{ Time } & \multirow{2}{*}{$\begin{array}{c}\text { Impulses } \\
\text { ortho-P+ } \\
\text { labile P } \\
\text { (from Table 1) } \\
\text { (\%) }\end{array}$} & \multicolumn{4}{|c|}{ Thereof } \\
\hline & & & $\begin{array}{c}\text { Ortho } \\
\left(K_{o}\right) \\
(\%)\end{array}$ & & $\begin{array}{l}\text { Labile } \\
\left(K_{L}\right) \\
(\%)\end{array}$ \\
\hline 2 min. & $94 \cdot 3$ & $62 \cdot 8$ & & $37 \cdot 2$ & \\
\hline & 93.5 & $51 \cdot 5$ & & $48 \cdot 5$ & \\
\hline 10 & $92 \cdot 4$ & $48 \cdot 6$ & & $51 \cdot 4$ & \\
\hline 26 & $95 \cdot 2$ & $46 \cdot 7$ & & $53 \cdot 3$ & \\
\hline 45 & $90 \cdot 1$ & $40 \cdot 0$ & & $60 \cdot 0$ & \\
\hline 65 & $84 \cdot 7$ & $43 \cdot 1$ & & $56 \cdot 9$ & \\
\hline 103 & $83 \cdot 1$ & $\mathbf{3 7 \cdot 4}$ & & $62 \cdot 6$ & \\
\hline $\begin{array}{l}3 \mathrm{hr} \text {. } \\
4\end{array}$ & $\begin{array}{l}81 \cdot 0 \\
82 \cdot 1\end{array}$ & $\begin{array}{l}38 \cdot 4 \\
36 \cdot 4\end{array}$ & $J_{o}=39.4$ & $\begin{array}{l}61 \cdot 6 \\
63 \cdot 6\end{array}$ & $J_{L}=60 \cdot 6$ \\
\hline 8 & $\begin{array}{l}73.7 \\
73.7\end{array}$ & 32.6 & & $67 \cdot 4$ & \\
\hline 16 & $74 \cdot 2$ & $41 \cdot 4$ & & 58.6 & \\
\hline 24 & 74.0 & $46 \cdot 4$ & & $53 \cdot 6$ & \\
\hline
\end{tabular}

(b) Ratio labile ATP phosphate/creatine phosphate

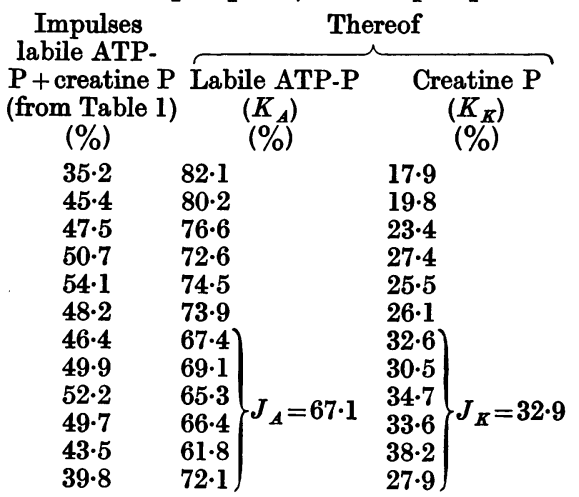

Table 1 shows that during the period of investigation the greater part of the newly introduced ${ }^{32} \mathrm{P}$ is present in the form of orthophosphate plus labile $P$. The distribution of activity at different times between these fractions is indicated in Table 2. This shows that the values of $K_{o}$ and $K_{L}$, which represent the relative activities of the orthophosphate and labile ester fractions respectively as percentages of the sum of the two at different times, move asymptotically toward constant levels $J_{O}$ and $J_{L}$ respectively, at which there is virtual equilibrium between the fractions in question. True equilibrium between two systems is attained-in a mathematical sense- only at infinity. In practice, however, this limiting value may be estimated by calculating the means of those experimental values which no longer show any analytically demonstrable systematic changes. These constant quotients may thus be regarded as being equal to the ratio of the actual phosphate concentrations in the two fractions. In this way we obtain from Table 2 for orthophosphate $\left(P_{o}\right)$ /labile phosphate $\left(P_{L}\right)$ :

$$
\frac{P_{o}}{P_{L}}=\frac{J_{o}}{J_{L}}=\frac{39 \cdot 4}{60 \cdot 6}=0.65,
$$

and for creatine phosphate $\left(P_{K}\right)$ /abile ATP $-\left(P_{A}\right)$

$$
\frac{P_{K}}{P_{A}}=\frac{J_{K}}{J_{A}}=\frac{32 \cdot 9}{67 \cdot 1}=0 \cdot 49,
$$

where $P_{K}$ and $P_{A}$ are the concentrations of the creatine phosphate and the labile ATP phosphate fractions, respectively, and $J_{K}$ and $J_{A}$ the relative activities of the fractions at equilibrium expressed as percentage of the sum of the two fractions.

Phosphate analyses gave the following values: $P$ after $10 \mathrm{~min}$. hydrolysis was $50.8 \pm 2.2 \mathrm{mg}$./ $100 \mathrm{mg}$. brain, and 'residual' $P$ was $19 \cdot 6 \pm 1 \cdot 0 \mathrm{mg}$./ $100 \mathrm{mg}$. brain. With the aid of the quotients obtained above (1 and 2) and of the concentration of phosphate after $10 \mathrm{~min}$. hydrolysis (which may be regarded as the sum of orthophosphate, creatine phosphate and labile ATP phosphate), the concentrations of these three fractions can be calculated. The values (Table 3) show fairly good agreement with those of Stone (1943) for mice.

The mathematical treatment of the results is made easier by the fact that - as was pointed out above-the exchange between the brain and the rest of the organism is extremely slow. The investigations of Hevesy \& Hahn (1940) referred to above show, for example, that the specific activity of the brain 215 min. after intravenous injection of ${ }^{32} \mathrm{P}$ in rats does not reach a higher level than $1.3 \%$ of the specific activity of the plasma measured at the same time. In agreement with these observations, it has been established at this laboratory (unpublished observations) that $1 \mathrm{hr}$. after intracisternal injection of ${ }^{32} \mathrm{P}$ in rabbits, the specific activity of the blood plasma amounts to only a small percentage of that of the brain. In view of the extremely intensive turnover in the brain (which even without any quantitative calculation is very evident from Table 1), these data would seem to indicate that the portion of the intracranially introduced phosphate which may be presumed to leave the brain during the course of the experiment is negligible and may be ignored in comparison with the amount which during

\begin{tabular}{|c|c|c|c|c|c|}
\hline & \multirow{2}{*}{ Animal } & Ortho-P & Creatine $\mathbf{P}$ & Labile ATP-P & 'Residual' P \\
\hline & & \multicolumn{4}{|c|}{ mg./100 g. brain } \\
\hline $\begin{array}{l}\text { Stone (1943) } \\
\text { This work }\end{array}$ & $\begin{array}{l}\text { Mouse } \\
\text { Rat }\end{array}$ & $\begin{array}{l}16 \cdot 9 \\
20 \cdot 0\end{array}$ & $\begin{array}{l}10 \cdot 1 \\
10 \cdot 1\end{array}$ & $\begin{array}{l}17 \cdot 2 \\
20 \cdot 7\end{array}$ & $\begin{array}{l}22 \cdot 5 \\
19 \cdot 6\end{array}$ \\
\hline
\end{tabular}

Table 3. Acid-soluble phosphate esters in brain 
the same period is turned over within the brain itself. In other words, this means that the ${ }^{32} \mathrm{P}$ content of the brain may be regarded as virtually constant throughout the experiment.

Although this fact simplifies the treatment considerably, there are still great difficulties in the way of calculation of the renewal rate of the various fractions. The complexity of the residual fraction consisting of various phosphate esters, containing possibly unknown precursors, renders an exact calculation of the turnover rate even of the 'pure' fractions impossible.

Nevertheless, an approximative evaluation of the order of magnitude of the renewal rate of the labile phosphate groups may be obtained by applying the following formula of Zilversmit, Entenman \& Fishler (1943)

$$
\frac{d K_{L}}{d t}=n \frac{K_{o}}{P_{o}}-n \frac{K_{L}}{P_{L}},
$$

in which $n$ signifies $\mu$ g. of labile $\mathrm{P}$ newly formed/ min./g. tissue, $K_{o}$ and $K_{L}$ the percentage of activity at time $t$ in the form of orthophosphate and labile phosphate, respectively, and $P_{O}$ and $P_{L}$ the phosphate content in the respective fractions expressed in $\mu \mathrm{g}$./g. tissue. By a rough approximation, which, however, with experiments of short duration does not constitute a grave source of error, one may put

$$
K_{o}+K_{L}=100 .
$$

Equation 3 may then be written

where

$$
K_{L}=J_{L}\left(1-e^{-n p t}\right) \text {, }
$$

and

$$
J_{L}=\frac{100 P_{L}}{P_{o}+P_{L}}=60 \cdot 6 \text {, }
$$

$$
p=\frac{P_{o}+P_{L}}{P_{o} P_{L}}=8.24 \times 10^{-3} .
$$

Thus from equation (5) we obtain for $n$ the expression

$$
n=\frac{\ln \frac{60 \cdot 6}{60.6-K_{L}}}{8.24 \times 10^{-3} t} .
$$

The calculation of $n$, using values for $K_{L}$ taken from Table 2 is shown in Table 4. An average value, $n=40$, shows fairly good agreement between the experimental and the values calculated according to equation (5). Thus about $40 \mu \mathrm{g}$. of labile $P$ were renewed/g. of brain/min.

Table 4. Calculation of the turnover rate for the labile phosphate esters in rat brain

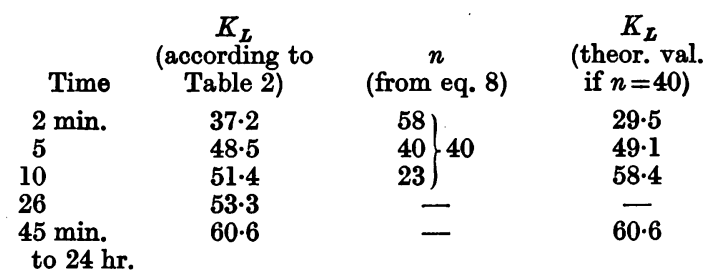

A comparison of this figure with corresponding values for some other organs is shown in Table 5. Although all the values given in this table should be regarded as highly approximate, they nevertheless show clearly that the capacity of brain to synthesize

\begin{tabular}{|c|c|c|}
\hline Tissue & $\begin{array}{l}\text { Renewed labile } \\
\mathrm{P} / \text { min./g. of } \\
\text { tissue } \\
(\mu \mathrm{g} .)\end{array}$ & Reference \\
\hline $\begin{array}{l}\text { ood corpuscles } \\
\text { ver }\end{array}$ & $\begin{array}{r}1 \\
15\end{array}$ & $\begin{array}{l}\text { Hevesy }(1939 a, b) \\
\text { Kalckar, Dehlinger \& } \\
\text { Mehler }(1944)\end{array}$ \\
\hline sscle & $\begin{array}{c}20-30 \\
40\end{array}$ & $\begin{array}{l}\text { Kalckar et al. (1944) } \\
\text { This work }\end{array}$ \\
\hline
\end{tabular}
energy-rich phosphate bonds is of the same order of magnitude as that of liver and muscle and may even exceed it.

Table 5. Comparison of the turnover rate for the labile phosphate esters in different tissues

It is implied in the foregoing calculation of the renewal rate of the labile phosphate esters that the equilibrium between creatine phosphate and the labile phosphategroups of ATP, is rapidly established. This assumption which is borne out by the findings of Lehmann (1936) requires that the ratio of the activity of the creatine phosphate and that of the labile ATP phosphate is constant all the time. Examination of Table 2 shows, however, that this is not entirely true. It will readily be seen from this table that creatine phosphate attains 'half equilibrium'* after 2 min. It is therefore to be expected that the activity after 5 min. should be $82 \%$ and after $10 \mathrm{~min}$. more than $99 \%$ of that found at complete equilibrium and this is not the case at all. An explanation of the anomaly might conceivably be that this fraction contains two different compounds: 'true' creatine phosphate, with rapid

* A particularly useful expression in treatment of equilibrium problems is that of 'half equilibrium time' which designates the time at which

$$
K=\frac{J}{2} \text {. }
$$

For the 'half equilibrium time' one thus obtains the expression

$$
t_{1}=\frac{\ln 2}{n p} \text {. }
$$

In simple cases (like those treated here) $t_{t}$ may be read directly, from the table, after which it is easy to calculate $n$. A general formulation of $(b)$ is

$$
t_{a}=\frac{\ln (1-a)^{-1}}{n p},
$$

in which $a$ means that part of the equilibrium value which has been reached at the time in question. From $(b)$ and $(c)$ we obtain

$$
a=1-2^{-t_{a} / t_{2}} \text {. }
$$

This formula is used in the treatment of the creatine phosphate fraction. 
renewal rate, corresponding to the steeply ascending component of the equilibrium curve; and an extremely easily hydrolysable phosphate ester with lower turnover rate. The solution of this problem however, will require further study.

\section{SUMMARY}

1. ${ }^{32} \mathrm{P}$ injected intracranially is turned over very rapidly in the rat brain. After injection for $2 \mathrm{~min}$. $40 \%$ of the newly introduced phosphate is in organic linkage. This figure increases to $70 \%$ in $8 \mathrm{hr}$., after which it becomes approximately constant.
2. The organically bound radioactive phosphate is found, during the period of the investigation, chiefly in the form of adenosinetriphosphate and creatine phosphate. The labile phosphate groups are renewed at an approximate rate of $40 \mu \mathrm{g} . \mathrm{P} / \mathrm{min} . / \mathrm{g}$. of brain. The value is compared with corresponding figures taken from the literature for liver and muscle.

This work has been supported by a grant of the Swedish Research Council. We are indebted to A. Bonkáló, M.D., who has worked out the method for the intracranial injection and who has helped us with these injections.

\title{
REFERENCES
}

Bailey, K. (1942). Biochem. J. 36, 121.

Bakay, L. \& Lindberg, O. (1949). Acta Physiol. scand. 17, 180.

Borell, U. \& Örström, A. (1947). Biochem. J. 41, 398.

Briggs, A. P. (1922). J. biol. Chem. 53, 13.

DuBois, K. P. \& Potter, V. R. (1943). J. biol. Chem. 150, 185.

Fiske, C. H. \& Subbarow, Y. (1925). J. biol. Chem. 66, 375. Herbert, D., Gordon H., Subrahmanyan, V. \& Green, D. E. (1940). Biochem. J. 34, 1108.

Heresy, G. (1939a). J. chem. Soc. p. 1213.

Hevesy, G. $(1939 b)$. K. danske vidensk. Selsk. Medd. 14, no. 5 .
Hevesy, G. \& Hahn, L. (1940). K. danske vidensk. Selsk. Medd. 15, no. 7.

Kalckar, H. M. (1944). J. biol. Chem. 153, 355.

Kalckar, H. M., Dehlinger, J. \& Mehler, A. (1944). J. biol. Chem. 154, 275.

Lehmann, H. (1936). Biochem. Z. 286, 336.

LePage G. A. (1946). Amer. J. Physiol. 146, 7276.

Lindberg, O. (1946). Ark. Kemi Min. Geol. 23A, no. 2.

Reiss, M., Badrick, F. E. \& Halkerston, J. H. (1949). Biochem. J. 44, 257.

Stone, W. E. (1943). J. biol. Chem. 149, 29.

Zilversmit, D. B., Entenman, C. \& Fishler, M. C. (1943). J. gen. Physiol. 26, 325.

\section{The Determination of $N$-Methyl-2-pyridone-5-carboxylic Acid in Human Urine}

\author{
By W. I. M. HOLMAN AND D. J. DE LANGE \\ The South African Institute for Medical Research, Johannesburg
}

(Received 19 July 1949)

Methods were recently described (Holman \& de Lange, 1949) for the determination of $N$-methyl-2. pyridone-3-carboxylamide and $N$-methyl-2-pyridone-5-carboxylamide in human urine. It was shown that the former compound has no significance in nicotinic acid metabolism, but that the latter is an important metabolite. Since there is a possibility that the 2:5-amide may be converted into the corresponding acid in the body, or in urine on storage, it seemed important to devise a method for the determination of the acid and to establish definitely whether or not it is present in urine.

It was previously observed that the 2:5-acid gave the same colour reaction as was used for the determination of the 2:5-amide, but that the acid was not extracted by chloroform from aqueous sodium hydroxide and therefore could not interfere in the method for the 2:5-amide. On further experimentation it was found that the acid could be readily ex- tracted from 10N-hydrochloric acid by one hundred volumes of ether. The amide was also extracted, but only to a small extent, the amount being negligible from normal urines. An appreciable amount was extracted from urines of exceptionally high amide content. In these cases it was possible to apply a correction for the amount of amide extracted by determining the recovery of a known amount of the amide added to the sample of urine and by determining separately the amide content of the sample. A method for the determination of the acid was worked out on these principles.

\section{METHODS}

The procedure, which was a modification of that previously described for the amide, was as follows:

Adsorption on Lloyd's reagent. Twenty-four $\mathrm{hr}$. specimens of urine of 1500-2000 ml., as used for the determination of the 2:5-amide, were diluted with an equal volume of water 